\title{
SMOS SATELLITE INFERENCE OF ALKALINITY OVER MEDITERRANEAN BASIN
}

\author{
Roberto Sabia ${ }^{1}$, Estrella Olmedo ${ }^{2}$, Antonio Turiel ${ }^{2}$, Justino Martinez ${ }^{2}$ \\ ${ }^{1}$ Telespazio-Vega UK Ltd. for European Space Agency, Frascati, Italy \\ ${ }^{2}$ BEC \& Institute of Marine Sciences, CSIC, Barcelona, Spain
}

\begin{abstract}
Novel SMOS satellite estimates of Sea Surface salinity in the Mediterranean Sea will be used to infer the spatial and temporal distribution of Alkalinity in this basin, exploiting the direct relationship between salinity and alkalinity. A proper validation of the derived variable will be performed against in-situ data, climatologies and model outputs. The resulting estimates of alkalinity in the Mediterranean Sea will be linked to the overall carbonate system in the broader context of ocean acidification assessment.
\end{abstract}

Index Terms - SMOS, Salinity, Alkalinity, Mediterranean Sea, Carbonate system, Ocean Acidification

\section{SMOS SALINITY AND THE MEDITERRANEAN SEA}

The European Space Agency (ESA) Soil Moisture and Ocean Salinity (SMOS) satellite, launched in 2009, carries an innovative microwave radiometer to capture images of brightness temperature. These images correspond to microwave radiation emitted from Earth's surface and can be related to soil moisture and ocean salinity [1].

Measurements of Sea Surface Salinity (SSS) are crucial being one of the main drivers of ocean circulation and closely connected with the cycling of freshwater around the planet. Tracking changes in salinity also help understand how our oceans are responding to climate change.

The Mediterranean Sea is an ideal laboratory to study ocean dynamics. Here, ocean processes occur over much shorter timescales and over smaller areas than the large oceans. The Mediterranean Sea experiences dramatic changes in its oceanographic and biogeochemical conditions derived from natural and anthropogenic forces. On a biogeochemical perspective, it is prone to absorb and store anthropogenic carbon due to the particular $\mathrm{CO} 2$ chemistry and the active overturning circulation.

When SMOS was designed almost twenty years ago, it wasn't envisaged that it could be used to map salinity in the Mediterranean Sea, a small semi-enclosed sea where the satellite signal suffer from several contaminations, and sea surface salinity was expected to be measured only in the open oceans. However, recent developments in the way of processing data allow SMOS to reveal salinity patterns and variability in this relatively small sea.

SMOS salinity data in the Mediterranean experienced until recently two limitations. The biggest issue was the socalled 'land-sea contamination', due to the fact that the observations taken over the surrounding land determine a signal leakage into the ocean data, limiting acquisitions over the coastal regions of a basin that is already relatively small.

The other issue was related to Radio Frequency Interference (RFI), especially near the Libyan coast and in the eastern part of the basin. Despite more than $75 \%$ of the RFI sources have been mitigated over the course of the mission lifetime globally (by working with national frequency protection authorities), some regions remain to be contaminated by RFI, especially the Middle East and some parts of Asia, besides the Mediterranean itself.

With more than eight years' of SMOS data to work with, scientists at the Barcelona Expert Center (BEC) in Spain has addressed both the problem of land-sea contamination and RFI in this area by applying a different strategy to the standard data processing chain. The new processing approach implies going back to each individual measurement of brightness temperature and working with the statistical distribution of the retrieved SSS data, after adequately debiasing the data [2]. This strategy have now allowed retrieving SSS in the Mediterranean with a reasonable uncertainty (around $0.4 \mathrm{psu}$ ), with characteristic time scales of several days and spatial scales of $25 \mathrm{~km}$. There are still some residual biases in the inversion, but the present state of the technique already allows the characterization of mesoscale dynamics in some part of the Mediterranean basin.

Scientists at the University of Liege, in Belgium, have also developed a method to better distinguish between real geophysical salinity and signal noise, improving the characterization of salinity in specific basins, including the Mediterranean Sea [3].

These studies now bring out the great potential of SMOS data even in areas for which the radiometer was not designed in the first place, extending even further the large 
catalogue of oceanographic applications that SMOS can support for science and operational applications.

\section{OCEAN ACIDIFICATION, CARBONATE SYSTEM AND ALKALINITY}

Oceans absorb almost one third of the carbon emissions injected into the atmosphere, acting as a natural carbon dioxide $(\mathrm{CO} 2)$ sink and playing a crucial role in slowing the rate of increase of atmospheric $\mathrm{CO} 2$ concentration.

However, this $\mathrm{CO} 2$ uptake has the overall effect of lowering the ocean $\mathrm{pH}$ and altering the chemical speciation of the large reservoirs of inorganic carbon dissolved in seawater. The overall process, referred to as Ocean Acidification (OA), affects the biogeochemical cycles and threatens marine biodiversity and its commercial exploitation.

As such, Ocean Acidification is nowadays gathering increasing attention as a major focus of climate-related research [4], with profound impact not only at scientific level, but also in its socio-economic dimension.

Growing international efforts are being devoted to develop a coordinated strategy for systematically monitoring $\mathrm{OA}$, with an eager need for global and frequent observations of OA-relevant parameters. Remote sensing technology is yet to be fully exploited [5] and can be integrated in this framework by providing synoptic and frequent OA-related observations on different spatial/temporal scales.

The exploration of the applicability of existing parameterizations to derive OA-related products exploiting EO data is currently ongoing [6]; synoptic observations of a suite of physical and biological satellite-derived parameters can certainly provide valuable information on processes controlling the distribution of carbonate system species within the surface ocean.

In principle, relevant information concerning OA from space can be obtained by especially exploiting the information content Sea Surface Temperature (SST) and Sea Surface Salinity (SSS) parameters. A proper integration of these different satellite datasets may allow to compute at least two and preferably three independent proxies among the four parameters constituting the seawater carbonate system: namely, 1) the partial pressure of $\mathrm{CO} 2$ in surface seawater $(\mathrm{pCO} 2) ; 2)$ the total alkalinity (TA - the charge difference between conservative cations and anions); 3 ) the total Dissolved Inorganic Carbon (DIC, equal to the sum of aqueous $\mathrm{CO} 2$ gas, carbonic acid, bicarbonate and carbonate ions) and 4) the $\mathrm{pH}$ itself.

These carbonate system parameters can be calculated by using numerical routines for inorganic carbon speciation computation, which produce also the saturation state $(\Omega)$ of calcite and aragonite.

In [7], efforts have been mainly focused on the derivation of TA and DIC estimates with a broad suite of different satellite, in-situ and modelled inputs. The main results indicate that remotely-sensed inference of OArelated parameters is promising, calling for sustained and increasing research efforts in this area.

In this context, alkalinity is a very relevant variable, being a measure of the capabilities of seawater to buffer acidification. Therefore, different ocean basins/regions present different responses to ocean acidification also as a consequence of specific alkalinity conditions.

\section{METHODOLOGY AND EXPERIMENTS}

In the surface ocean, Total Alkalinity (TA) is largely controlled by salinity. TA can be measured directly on seawater samples and is mainly defined by three chemical constituents (bicarbonate, carbonate, and boron compounds) that increase and decrease proportionately to salinity.

As TA and salinity are so well correlated, several authors studied the relationship and possible derivation of TA as a function of (mainly) SSS, namely [8 and 9]. An attempt of deriving TA in open ocean with one or both formulations by using satellite measurements of SSS as forcings has been performed in [7 and 10]. Additionally, estimates of TA from the NASA Aquarius satellite have also been performed by [11].

None of these formulations however were specifically tailored for the Mediterranean Sea, and the lack of satellite SSS data prevented anyway a routine derivation of SSS and subsequently TA in this basin. Furthermore, there is still debate in the literature of which formulation shall be the most adequate for the conditions encountered in the Mediterranean basin and its sub-regions, as described in [12, 13].

In this paper, the formulations above will be implemented with the objective of deriving systematically TA in the Mediterranean basin starting from the the novel SMOS SSS estimates that are recently available from the BEC and University of Liege institutes mentioned above.

At least one year of Level-3 (spatio-temporal averaging of single satellite overpass over a specific spatial and temporal window) data will be used to characterize the signal variability over a seasonal timeframe.

The resulting TA maps will be compared with the available in-situ measurements (as coming from RV cruises data), with existing climatologies and with reliable biogeochemical model outputs, such as [14]. By this validation exercise, a twofold objective of verifying the consistency of this approach and establishing which formulations is the most adequate for this specific region (or any sub-region) will be addressed.

In a longer-term perspective, estimates of TA in the Mediterranean Sea will be linked to the remaining carbonate system parameters, and inference about the overall biogeochemical system and the related OA phenomenon can be obtained. 


\section{REFERENCES}

[1] J. Font et al., "SMOS: The Challenging Sea Surface Salinity Measurement From Space," in Proceedings of the IEEE, vol. 98, no. 5, pp. 649-665, May 2010. doi: 10.1109/JPROC.2009.2033096

[2] Olmedo, E., J. Martinez, A. Turiel, J. Ballabrera-Poy, and M. Portabella, "Debiased non-Bayesian retrieval: A novel approach to SMOS Sea Surface Salinity". Remote Sensing of Environment 193, 103-126 (2017).

[3] Alvera-Azcárate, A., A. Barth, G. Parard, J.-M. Beckers, Analysis of SMOS sea surface salinity data using DINEOF, In Remote Sensing of Environment, Volume 180, 2016, Pages 137145, ISSN 0034-4257, https://doi.org/10.1016/j.rse.2016.02.044.

[4] Doney, S.C., Victoria J. Fabry, Richard A. Feely, and Joan A. Kleypas, Ocean Acidification: The Other CO2 Problem, Annu. Rev. Mar. Sci. 2009. 1:169-92, DOI: 10.1146/annurev.marine.010908.163834.

[5] Gledhill, D.K., R. Wanninkhof, and C.M. Eakin. 2009. Observing ocean acidification from space. Oceanography 22(4):48-59

[6] Land, P., J. Shutler, H. Findlay, F. Girard-Ardhuin, R. Sabia, N. Reul, J.-F. Piolle, B. Chapron, Y. Quilfen, J. Salisbury, D. Vandemark, R. Bellerby, and P. Bhadury, "Salinity from space unlocks satellite-based assessment of ocean acidification", Environmental Science \& Technology, DOI: 10.1021/es504849s, Publication Date: February 8, 2015.

[7] Shutler, J., P. Land, H. Findlay, F. Girard-Ardhuin, J.-F. Piolle, N. Reul, B. Chapron, Y. Quilfen, J. Salisbury, D. Vandemark, R. Bellerby, P. Bhadury, R. Sabia, D. Fernandez, Monitoring the variability of the surface marine carbonate system from space10th International Carbon Dioxide Conference, 21-25 August 2017 Interlaken, Switzerland.

[8] Lee, K., et al. "Global relationships of total alkalinity with salinity and temperature in surface waters of the world's oceans." Geophysical Research Letters 33.19 (2006).

[9] Takahashi, T., S. C. Sutherland, D. W. Chipman, J. G. Goddard, T. Newberger and C. Sweeney. 2014. Climatological Distributions of $\mathrm{pH}, \mathrm{pCO} 2$, Total $\mathrm{CO} 2$, Alkalinity, and $\mathrm{CaCO} 3$ Saturation in the Global Surface Ocean. ORNL/CDIAC-160, NDP094. Carbon Dioxide Information Analysis Center, Oak Ridge National Laboratory, U.S. Department of Energy, Oak Ridge, Tennessee. doi: 10.3334/CDIAC/OTG.NDP094.

[10] Sabia, R., D. Fernández-Prieto, J. Shutler, C. Donlon, P. Land, N. Reul, Remote Sensing of Surface Ocean $\mathrm{pH}$ Exploiting Sea Surface Salinity Satellite Observations, IGARSS ' 15 (International Geoscience and Remote Sensing Symposium), Milano, Italy, July $27-31,2015$.

[11] Fine, R. A., D. A. Willey, and F. J. Millero (2017), Global variability and changes in ocean total alkalinity from Aquarius satellite data, Geophys. Res. Lett., 44, 261-267, doi:10.1002/2016GL071712.
[12] Schneider, A., D.W. R. Wallace, and A. Kortzinger (2007), Alkalinity of the Mediterranean Sea, Geophys. Res. Lett., 34, L15608, doi:10.1029/2006GL028842

[13] Álvarez, M., Sanleón-Bartolomé, H., Tanhua, T., Mintrop, L., Luchetta, A., Cantoni, C., Schroeder, K., and Civitarese, G.: The $\mathrm{CO} 2$ system in the Mediterranean Sea: a basin wide perspective, Ocean Sci., 10, 69-92, https://doi.org/10.5194/os-10-69-2014, 2014.

[14] Cossarini, G., Lazzari, P., and Solidoro, C.: Spatiotemporal variability of alkalinity in the Mediterranean Sea, Biogeosciences, 12, 1647-1658, https://doi.org/10.5194/bg-12-1647-2015, 2015. 